\title{
Genetic gain in perennial ryegrass forage yield in Australia and New Zealand
}

\author{
M. HARMER ${ }^{1}$, A.V. STEWART ${ }^{2}$ and D.R. WOODFIELD ${ }^{2}$ \\ ${ }^{1} P G G$ Wrightson Seeds Ltd, Leigh Creek Research Centre, Leigh Creek, VIC 3352, Australia \\ ${ }^{2} P G G$ Wrightson Seeds Ltd, Kimihia Research Centre, Lincoln 7676, New Zealand \\ mharmer@pgwseeds.com.au
}

\begin{abstract}
Genetic gain of forage yield in pasture species underpins long-term productivity improvements in pastoral agriculture. The value of proprietary seed sales in Australia and New Zealand has resulted in more public and private investment in perennial ryegrass breeding than other forage species, but this is still much less than for major row crops. Historic estimates of genetic gain in total annual dry matter (DM) yield for perennial ryegrass cultivars have ranged from 0.25 to $0.73 \%$ per year, but ongoing questions from farmers and industrygood organisations has prompted further assessment of recent genetic gains. Analysis of 46 Australian and New Zealand trials identified two distinct periods of genetic gain: (a) before 1990, where genetic gain for total annual DM yield was limited, and (b) after 1990 where consistent genetic gains of approximately $0.76 \%$ per year or $105 \mathrm{~kg} \mathrm{DM} / \mathrm{ha} /$ year have occurred, with rates higher than this especially in winter, summer and autumn. Investigations to better understand the key scientific and economic factors responsible for the observed changes in rates of genetic gain are warranted, as this may help inform policies and investment aimed at further increasing rates of genetic gain in all forage species.
\end{abstract}

Keywords: germplasm origin, endophyte, Lolium perenne L., plant intellectual property rights, cultivar evaluation

\section{Introduction}

Improvement of perennial ryegrass (Lolium perenne) agronomic performance is of considerable importance to Australian and New Zealand farmers (Lee et al. 2012), and attracts both public and private investment. The companies involved in plant breeding focus on cultivar development and endophyte technology. The larger government investments focus on germplasm collection and new plant breeding tools, for instance, marker assisted selection and genomic selection (Hayes et al. 2013). A better understanding of the key factors influencing rates of genetic gain is needed to guide future investments. Woodfield (1999) reviewed three New Zealand publications and reported rates of gain in total annual forage yield of $0.25,0.6$ and $0.73 \%$ per year. Analysis of 17 trials by Easton et al.
(2002) determined that the rate of gain for DM yield in cultivars released before 1996 was 0.4 and $0.7 \%$ per year for total and summer/autumn yield, respectively. Wilkins \& Humphreys (2003) estimated that genetic gain in European perennial ryegrasses ranged from 0.25 to $0.6 \%$ per year, however, these estimates were for cultivars with different seasonal growth patterns to local cultivars. The low value of late spring growth compared to the high value of winter, early spring, summer and autumn growth in New Zealand and Australia has meant breeders have developed cultivars with different seasonal growth patterns to the Europeans. This is reflected in the values underlying the New Zealand Forage Value Index (FVI) calculations (Chapman et al. 2016). This study aims to estimate current rates of genetic gain in contemporary perennial ryegrass cultivars of relevance to Australian and New Zealand farmers by utilising consolidated data from the largest number of trials contributing to any published estimate to date.

\section{Methods \\ Data set}

The analysis was based on 46 replicated field trials spanning 25 years, 34 from New Zealand and 12 from Australia. The majority of these trials utilised cutting and drying of herbage (as per National Forage Variety Trials), however, some rising plate meter and pasture probe measured trials were also included. The trials analysed covered a broad time span (to include older cultivars), have a number of common cultivars that allowed analysis across trials (allowing estimates of genetic gain over time) and represent the main agroclimate zones where perennial ryegrass is commonly grown in Australia and New Zealand.

The trials contained data on 91 cultivars, and included almost every cultivar commercialised in Australia and/ or New Zealand over the past 45 years. The data set represents all major germplasm types (i.e. New Zealand, European and in particular north-west Spain) (Stewart 2006), diploids and tetraploids, various heading dates (early to late) and contain all locally commercialised endophytes. The cultivars marketed in Australia that were not included were functionally similar to the low yielding Australian naturalised ecotypes 'Victorian' and 'Kangaroo Valley'. Data on the pre-1970 New Zealand 
cultivars 'Grasslands Ruanui' and 'Grasslands Ariki' were also not included, however, it is considered that their absence did not have a major impact on the ability to estimate rates of genetic gain.

\section{Analysis}

Establishment periods were excluded from the analysis as many trials were managed to ensure good establishment of all lines; thus, the results represent growth and persistence of established swards. The aim was to estimate more broadly the overall rates of genetic gain in Australia and New Zealand rather than look at the genotype by environment interactions which could form the basis of a future paper. Yields were partitioned on a pro rata basis into: winter (June, July), early spring (August, September), late spring (October, November), summer (December, January, February) and autumn (March, April, May). The split of late winter and spring into early and late spring, reflects the industry accepted differences in growth patterns observed at the pre- and post-flowering growth stages and aligns with DairyNZ's approach to data analysis within the FVI (Chapman et al. 2016). Each season for each trial was analysed using the Bayesian Information Coefficient (Schwarz 1978) statistic that indicates best fits for the trial data (either randomised block, row-column or nearest neighbour, the latter two using REML). The resulting means for each trial were used in an unweighted general linear model, fitting trial and cultivar effects. The rate of genetic gain was determined by fitting cultivar yields as a function of year of commercialisation.

Estimates of the rate of gain were made utilising all cultivars for which data were available. Previous estimates by Woodfield (1999) and Easton et al. (2002) were made utilising cultivars bred for and used in New Zealand. In contrast, the data set used here contained many more cultivars that have been marketed in
Australia and New Zealand over recent years, many of which were of questionable agronomic worth, possibly due to the absence of accepted independent cultivar evaluation schemes for Australian producers and New Zealand's sheep and beef producers. The existence of these lower yielding cultivars should not confound estimates of genetic gain, necessitating a different approach to estimating genetic gain than merely regressing performance of all marketed cultivars over time. Thomson (2014) faced the same issue when determining the rate of genetic gain for yield in Australian cereals, as that marketplace is characterised by large numbers of cultivars, with some of questionable agronomic worth. Thomson (2014) suggested that firms commercialising cereal cultivars with less agronomic merit may be encouraged to do so by the end-point royalties available to cereal breeders. To remove the confounding effect of this proliferation of cultivars of dubious agronomic worth, Thompson (2014) estimated genetic gain by defining it as the regression over time of the performance of the best available cultivars.

A similar approach was used here. Rate of genetic gain was defined as a regression over time of the series of best available cultivars, i.e. the first available (the incumbent), the next to be released that had better performance (which becomes the new incumbent) and so on; these were defined as 'frontier cultivars'. To reduce uncertainty about the direction and and rate of genetic gain by increasing the number of cultivars in the frontier, products commercialised after an incumbent were included when their yield was within one standard error of the incumbent. This divides the market place into: cultivars which comprise the frontier of genetic gain in which iterative improvements in product performance have occurred (solid circles in Figures 1 to 6); and also-ran cultivars commercialised and marketed to farmers for other reasons (open circles in Figures 1 to 6).

Table 1 Genetic gain in cultivar yield up to and including 1990 and those commercialised after 1990.

\begin{tabular}{|c|c|c|c|c|c|}
\hline & \multicolumn{4}{|c|}{ Annual genetic gain } & \multirow{3}{*}{$\begin{array}{l}\text { Correlation with total yield } \\
\mathbf{R}^{2}\end{array}$} \\
\hline & \multicolumn{2}{|c|}{ Pre-1990 } & \multicolumn{2}{|c|}{ Post-1990 } & \\
\hline & kg DM/ha/year & $\%$ & kg DM/ha/year & $\%$ & \\
\hline Total yield & $2 \pm 9^{N S}$ & - & $105 \pm 11^{* *}$ & 0.76 & - \\
\hline Winter & $1 \pm 3^{N S}$ & - & $14 \pm 2^{* *}$ & 1.01 & $0.59^{* *}$ \\
\hline Early Spring & $-3 \pm 3^{N S}$ & - & $23 \pm 4^{* *}$ & 0.81 & $0.02^{N S}$ \\
\hline Late Spring & $4 \pm 6^{\mathrm{NS}}$ & - & $20 \pm 3^{* *}$ & 0.50 & $0.53^{* *}$ \\
\hline Summer & $3 \pm 6^{N S}$ & - & $35 \pm 5^{\star \star}$ & 1.13 & $0.81^{* *}$ \\
\hline Autumn & $5 \pm 3^{N S}$ & - & $34 \pm 4^{* \star}$ & 1.28 & $0.86^{\star *}$ \\
\hline
\end{tabular}

NS=not significant, ${ }^{*}=\mathrm{P}<0.01$. 


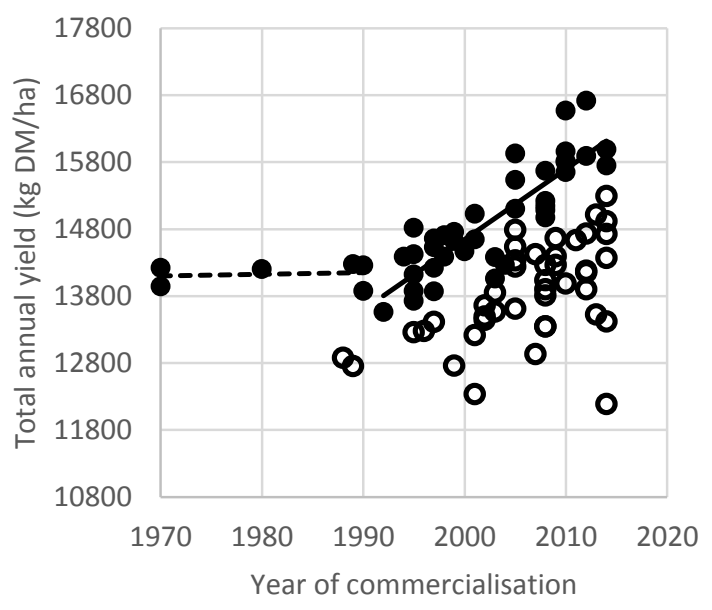

Figure 1 Genetic gain - total annual yield. Closed circles $(\bullet)$ are cultivars at the frontier of genetic gain; open circles (o) are cultivars not at the frontier of genetic gain; the dashed line is the rate of gain up to and including 1990 and the solid line genetic gain after 1990.

Whenever mentioned, percentage genetic gain has been determined as a function of average herbage yields of cultivars commercialised before 1990, as this was the approximate denominator used by Woodfield (1999) and Easton et al. (2002), i.e. the annual improvement in cultivar performance (numerator) was divided by the average performance of cultivars commercialised before 1990 (denominator). The denominator could be incrementally adjusted up over time to reflect some other group of cultivars (perhaps contemporary and higher yielding cultivars), but doing so whilst absolute gains ( $\mathrm{kg} \mathrm{DM} /$ ha/year) remain the same would over time trend percentage gains downward and towards zero.

The ecotype Victorian SE was excluded from the analysis, although first certified in 1930, it represents a range of different ecotypes with poor performance. Further, due to its early date of commercialisation (1930) it would exert far too much influence on the regressions.

\section{Results}

The total annual yields of cultivars were found to be highly correlated $(\mathrm{P}<0.001)$ with their winter, late spring, summer and autumn yields, suggesting gains in total annual yield have occurred via yield increases in these seasons (Table 1). Total annual yield was not correlated $(\mathrm{P}>0.05)$ with early spring yield.

\section{Total annual yield}

Linear regression of total annual yield on the year of commercialisation over the last 45 years suggests

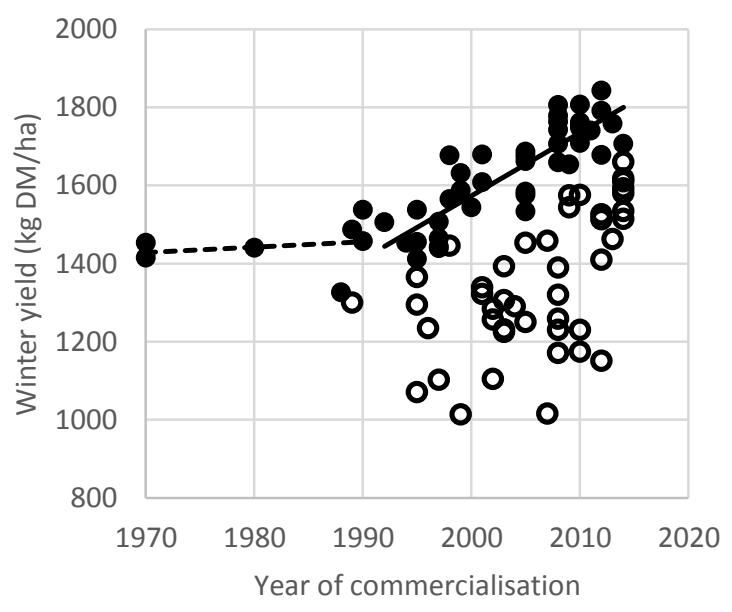

Figure 2 Genetic gain - winter yield. Refer to Figure 1 notes.

genetic gain averaged $58 \pm 8 \mathrm{~kg} \mathrm{DM} / \mathrm{ha} /$ year $\left(\mathrm{R}^{2}=0.74\right.$, $\mathrm{P}<0.01$ ), however, this does not fully reflect the genetic gains in total annual yield made in more recent years (Figure 1). Analysis of progress pre-1990 and post1990, shows genetic gain has predominantly occurred post-1990. Cultivars commercialised pre-1990 have non-significant $(\mathrm{P}=0.81)$ gain of $2 \pm 9 \mathrm{~kg} \mathrm{DM} / \mathrm{ha} /$ year. In contrast, post-1990 cultivars have an annual yield increase of $105 \pm 11 \mathrm{~kg} \mathrm{DM} / \mathrm{ha} /$ year $(\mathrm{P}<0.001)$ or $0.76 \%$ per year.

As two different phases of genetic gain have occurred, subsequent seasonal analysis of genetic gain considers the pre- and post-1990 regressions separately.

\section{Winter}

Annual change in winter growth rates in pre-1990 cultivars was minimal and non-significant $(\mathrm{P}=0.68)$ at $1 \pm 3 \mathrm{~kg} \mathrm{DM} / \mathrm{ha} /$ day (Table 1). Post-1990 gains were significant $(\mathrm{P}<0.01)$ for winter growth with a rate of $14 \pm 2 \mathrm{~kg} \mathrm{DM} / \mathrm{ha} /$ year or $1.01 \%$ per year. These regressions and the winter yield of all cultivars are presented in Figure 2. Figures 3 to 6 present the same regressions (pre- and post-1990) and yield data for the other seasons discussed below.

\section{Early spring}

Pre-1990 cultivars did not have significant $(\mathrm{P}=0.36)$ improvement in early spring growth, however, the early spring performance of post-1990 cultivars improved significantly $(\mathrm{P}<0.01)$ by $23 \pm 4 \mathrm{~kg} \mathrm{DM} /$ ha/year (Figure 3 ) or $0.81 \%$ per year.

\section{Late spring}

Genetic gains in late spring yield are not apparent $(\mathrm{P}=0.52)$ in pre-1990 cultivars, while the genetic gain in post-1990 cultivars was $20 \pm 3 \mathrm{~kg} \mathrm{DM} / \mathrm{ha} /$ year $(\mathrm{P}<0.01)$ (Figure 4 ), or $0.50 \%$ per year. 


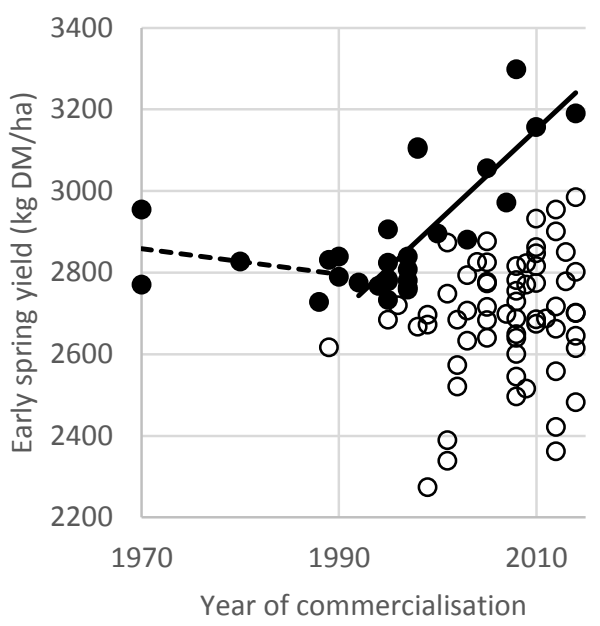

Figure 3 Genetic gain - early spring yield. Refer to Figure 1 notes.

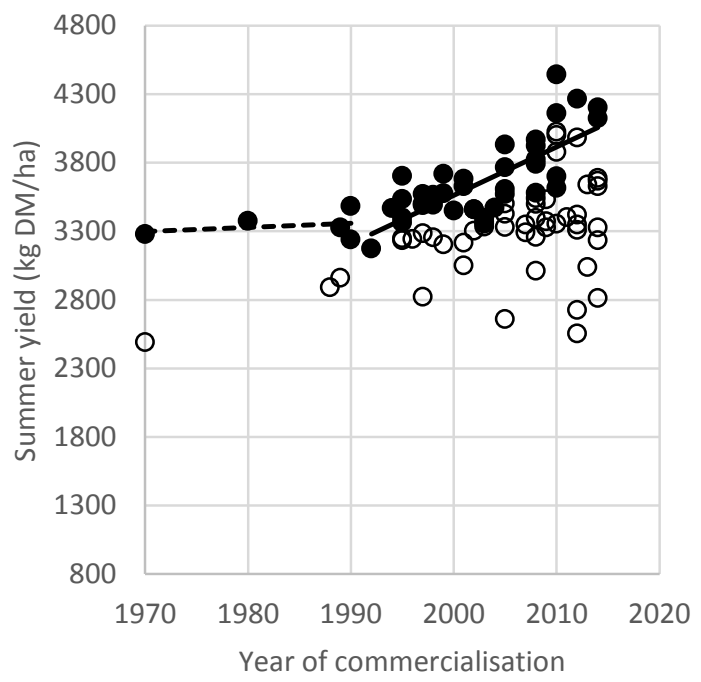

Figure 5 Genetic gain - summer yield. Refer to Figure 1 notes.

\section{Summer}

Herbage yield in summer did not increase significantly $(\mathrm{P}=0.65)$ in pre-1990 cultivars (Figure 5), but post1990 cultivars had significant gains $(\mathrm{P}<0.01)$ of $35 \pm 5$ $\mathrm{kg} \mathrm{DM} /$ ha/year or $1.13 \%$ per year.

\section{Autumn}

Cultivars commercialised before 1990 had a nonsignificant $(\mathrm{P}=0.18)$ increase in autumn yield of $5 \pm 3 \mathrm{~kg}$ $\mathrm{DM} /$ ha/year (Figure 6). In contrast, the genetic gain in autumn herbage yield post-1990 was highly significant $(\mathrm{P}<0.01)$ at $34 \pm 4 \mathrm{~kg} \mathrm{DM} / \mathrm{ha} /$ year or $1.3 \%$ per year.

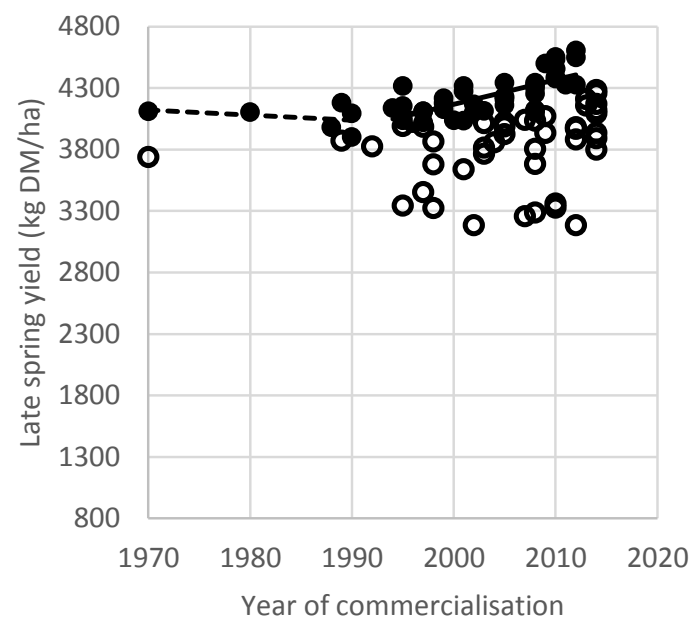

Figure 4 Genetic gain - late spring yield. Refer to Figure 1 notes.

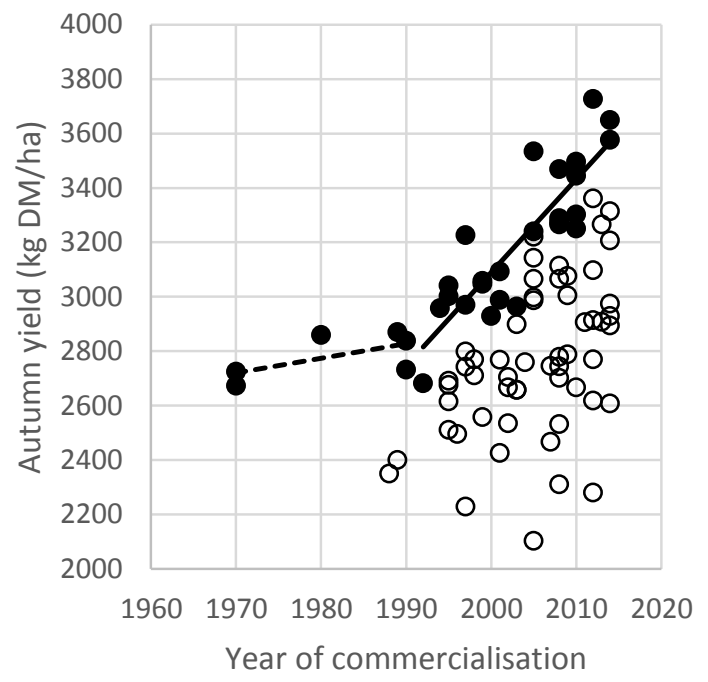

Figure 6 Genetic gain - autumn yield. Refer to Figure 1 notes.

\section{Discussion}

\section{Observed genetic gain}

These results provide strong evidence for consistent improvement in the performance of the frontier cultivars over the past 25 years.

The estimate of post-1990 genetic gain in total annual forage yield of $105 \pm 11 \mathrm{~kg} \mathrm{DM} / \mathrm{ha} /$ year or $0.76 \%$ per year was similar to the upper estimate of Woodfield (1999), while the estimates of seasonal genetic gain of up to $1.28 \%$ per year were lower than reported by Woodfield (1999). Total forage yield of cultivars was strongly correlated with their winter, late spring, summer and autumn growth but did not correlate with 
early spring growth (Table 1). This reflects the priority breeders have placed on improving growth in the seasons of low forage availability and consequently high forage value (Chapman et al. 2016) to reduce farms supplementary feed requirements and/or allow increased stocking rates. As ryegrass breeders have had the greatest success in seasons of high forage value, the real rate of genetic gain expressed in economic terms could exceed $0.76 \%$ per year.

The lack of correlation $\left(\mathrm{R}^{2}=0.02\right)$ between cultivars total annual and early spring yields (Table 1) strongly suggests cultivars with superior overall merit did not have genetic gain in early spring forage yield. Half (10) of the 20 early-spring post-1990 frontier cultivars are New Zealand-bred using germplasm naturalised in New Zealand, while nine are Australian naturalised germplasm commercialised predominantly in the late 1990s and 2000s. These nine cultivars were predominantly derived from early maturing Kangaroo Valley ecotypes which have strong early-Spring growth but not overall for total annual herbage yield compared to frontier cultivars. Thus, the observed gain may reflect a trend by some Australian firms of branding and marketing early maturing Kangaroo Valley ecotypes that have good early spring yield at the expense of all other seasons.

The discovery and delivery of novel endophytes has also had an important role in herbage yield and persistence gains since 1990. The forage yield and persistence of Australasian ryegrass cultivars is due to a combination of plant genetics and novel endophytes giving superior pest resistance (Hume \& Sewell 2014). Before the discovery of the role of endophyte in ryegrass staggers in grazing animals, and the role of the alkaloids produced by the endophyte in pest protection, the endophyte status of cultivars confounded interpretation of cultivar performance (Stewart 2006). Endophyte status was not considered and therefore not monitored in breeding programmes or in seed sold on the Australasian market. The discovery of the animal health and insect tolerance benefits has led to the commercialisation of a range of novel endophytes such as AR1, NEA2 and AR37 endophytes. Similarly changes in other important traits such as forage quality through later maturing cultivars, tetraploids and reduced incidents of crown and stem rust diseases have occurred.

Before 1990 no evidence was found for genetic gain in total annual yield or the herbage yield in any individual season. Woodfield (1999) reported a similar trend (two distinct stages of genetic gain) in white clover (Trifolium repens). It could be argued that this conclusion was possible because pre-1970s cultivars and ecotypes with lower yields were not included, but these findings do align with Easton et al. (2002) who reported no significant gain $(\mathrm{P}=0.54)$ in total yield during the same period. As stated above, the confounding effects of endophyte and the associated insect tolerance were a major impediment to breeders making progress on herbage yield and performance. From 1990 onwards, the understanding and use of novel endophytes have become integrated into ryegrass breeding programmes, and the confounding effects of endophyte has been removed.

\section{Scientific innovations, economic factors and observed genetic gain}

Scientific innovations responsible for observed gains may include: effective use of late flowering germplasm from north-west Spain by plant breeders (Stewart 2006); superior endophyte technology (Hume \& Sewell 2014) and tetraploidy. Commercialisation of cultivars with progressively later heading dates (Lee et al. 2012) and lower aftermath heading may explain some of the improvement in late spring, summer and autumn yield. The size of data sets now available (91 cultivars across 46 trials) makes possible an analysis to estimate the contribution of each of these scientific factors to observed genetic gain, this would be a valuable area for further research.

In addition to scientific innovations, the significant lift in genetic gain in post 1990 cultivars warrants consideration of economic (non-scientific) factors that can influence genetic gain. Private sector investment in forage plant breeding in New Zealand was stimulated by the advent of Plant Variety Rights legislation in 1973 and many new private breeding programmes came to fruition in the 1990s. The introduction of Plant Breeders Rights in Australia around the same time has probably had less impact on forage breeding investment in Australia. In both Australia and New Zealand, however, investment in public breeding programmes has reduced markedly in the past 20 years. In New Zealand public investment has been maintained in endophyte research and to a lesser degree in the development of pre-breeding and breeding tool development. This includes long-term investment in genetic modification, development of molecular markers and in application of genomic selection. In many cases these public funds have been matched with industry funding.

\section{The role of independent cultivar testing}

The genetic gains reported here in frontier cultivars reflect the increased herbage yields that are possible from use of elite cultivars, however, without a proven evaluation system it is not easy for farmers to identify these high performing cultivars amongst the array of cultivars on offer. Furthermore, these results demonstrate that many perennial ryegrass cultivars commercialised post-1990 have poor performance compared to the frontier cultivars. This phenomena 
is of particular concern for farmers and results in the independence and reliability of individual company results being frequently questioned.

The introduction of the National Forage Variety trials in the early 1990s under the auspices of the New Zealand Plant Breeding Association provided agreed evaluation protocols and some degree of independent data in the New Zealand market. This has now been taken to a higher level by the introduction of the FVI funded by DairyNZ (Chapman et al. 2016). This has not been the case in Australia where until the last few years there was no independent testing and companies relied predominantly on their own trials. This is changing with the introduction of the Pasture Trial Network involving Meat \& Livestock Australia and potentially Dairy Australia.

There is a need to be vigilant to ensure that these independent testing systems do actually reflect management practices that occur on-farm. There are many examples internationally where cultivar performance in national trialling systems is poorly correlated with on-farm performance. The current systems in New Zealand and Australia deal with the performance of ryegrass as a monoculture while its use on-farm is in mixtures with various clovers and herbs. This issue is being addressed as part of the on-going development of the Forage Value Index.

\section{ACKNOWLEDGEMENTS}

We thank the many Australian and New Zealand research staff at PGG Wrightson Seeds who collected the tens of thousands of data points that made this analysis possible. We also thank Dr David Baird of VSN (NZ) Ltd for assistance with the generation of yield analysis on a seasonal basis.

\section{REFERENCES}

Chapman, D.F.; Bryant, J.R.; Olayemi, M.E.; Edwards G.R.; Thorrold, B.S.; McMillan, W.H.; Kerr, G.A.;
Judson, G.; Cookson, T.; Moorhead, A.; Norriss, M. 2016. An economically based evaluation index for perennial and short-term ryegrasses in New Zealand dairy farm systems. Grass and Forage Science DOI: 10.1111/gfs.12213

Easton, H.S.; Amyes, J.M.; Cameron, N.E.; Green, R.B.; Kerr, G.A.; Norris, M.G.; Stewart A.V. 2002. Pasture plant breeding in New Zealand: where to from here? Proceedings of the New Zealand Grassland Association 64: 173-179.

Hayes, B.J.; Cogan, N.O.I.; Pembleton, L.W.; Goddard, M.E.; Wang, J.; Spangenberg, G.C.; Forster, J.W. 2013. Prospects for genomic selection in forage plant species. Plant Breeding 132: 133-143.

Hume, D.E.; Sewell, J.C. 2014. Agronomic advantages conferred by endophyte infection of perennial ryegrass (Lolium perenne L.) and tall fescue (Festuca arundinacea Schreb.) in Australia. Crop and Pasture Science 65: 747-757.

Lee, J.M.; Matthew, C.; Thom, E.R.; Chapman, D.F. 2012. Perennial ryegrass breeding in New Zealand: a dairy industry perspective. Crop and Pasture Science 63: 107-127.

Schwarz, G. 1978. Estimating the dimensions of a model. The Annals of Statistics 6: 461-464.

Stewart, A.V. 2006. Genetic origins of perennial ryegrass (Lolium perenne) for New Zealand pastures. pp. 11-20. In: Proceedings of the $13^{\text {th }}$ Australasian Plant Breeding Conference.

Thomson, R. 2014. The yield of plant variety protection. American Journal of Agricultural Economics 97: 762-785.

Wilkins, P.W.; Humphreys, M.O. 2003. Progress in breeding perennial forage grasses for temperate agriculture. Journal of Agricultural Science 140: 129-150.

Woodfield, D.R. 1999. Genetic improvements in New Zealand forage cultivars. Proceedings of the New Zealand Grasslands Association 61: 3-7. 